We welcome letters to the Editor concerning articles which have recently been published. Such letters will be subject to the usual stages of selection and editing; where appropriate the authors of the original article will be offered the opportunity to reply.

Letters should normally be under $\mathbf{3 0 0}$ words in length, doublespaced throughout, signed by all authors and fully referenced. The edited version will be returned for approval before publication.

(C)2007 British Editorial Society of Bone and Joint Surgery \$2.00 J Bone Joint Surg [Br] 2007;89-B:422-3.

\section{Infection in knee replacements after previous injection of intra-articular steroid}

Sir,

I read with interest the paper by Papavasiliou et $\mathrm{al}^{1}$ in the March 2006 issue entitled "Infection in knee replacements after previous injection of intra-articular steroid". The authors suggest that there is a significant increase in the incidence of post-operative deep infection with the prior use of intra-articular steroid. However, there are a number of points that detract from the power of this study that I would like to highlight. In the first instance the numbers shown are very small, and statistically significant differences based on three outcomes are questionable. Furthermore there were a number of variables that may be subject to bias, namely a different operating surgeon in each case, variable time between injection and surgery, and variable numbers of injections prior to surgery.

The authors also comment on the evidence, or rather the lack of it, that steroids do not provide lasting beneficial value in osteoarthritis. I think most would agree but that does not detract from the fact that they can provide good symptom control in the short term, perhaps delaying surgery until a more appropriate time.

I appreciate, as do the authors, the inherent weaknesses in a retrospective study such as this, and agree that a prospective study with more defined variables would lend weight to their argument.

Finally, I wonder whether the practice of the authors has changed in light of their results. Have they abandoned the use of intra-articular steroids?

doi:10.1302/0301-620X.89B3.19287

L. E. DODD, MRCS, Senior House Officer Plastic Surgery

Queen Victoria Hospital,

East Grinstead, UK.

1. Papavasiliou AV, Isaac DL, Marimuthu R, Skyrme A, Armitage A. Infection in knee replacements after previous injection of intra-articular steroid. J Bone Joint Surg $[B r]$ 2006;88-B:321-3

\section{Author's reply:}

\section{Sir,}

We thank Dr Dodd for his interest in our paper.

Infections in total knee replacement (TKR) are rare and depend on many factors, and one would need a very large study to demonstrate conclusively the connection between steroids and an increased risk of post-TKR infection. Our study though, demonstrates sufficient concern and concludes that the decision to administer intra-articular steroids to a patient who may be a candidate for knee replacement surgery should not be taken lightly.

Many centres should review their results retrospectively and report them. The variable time and number between steroid injection and time to surgery is one of the inherent limitations of any retrospective study. The important fact is that there seems to be an increased risk of infection in patients who have had a steroid injection in the 11-month period prior to TKR. This is of increased importance since the waiting list for a joint replacement in the United Kingdom is currently about six months. I believe that there is enough published data ${ }^{1-6}$ to show that intraarticular steroid injections show a positive effect that is only short-lived ( 1 to 4 weeks), and is confounded by a powerful response to placebo, and as such are of limited benefit in the long-term management of osteoarthritis $(\mathrm{OA})$ of the knee.

I agree that clinical experience shows that few patients achieve a significant and sustained response. The problem is that it is not possible to predict which patients will actually respond. ${ }^{7}$ Osteoarthritis is increasingly viewed as a phasic condition in which organ damage occurs intermittently. The ability to detect these phases of increased disease activity perhaps could in the future lead to a more rational approach to the use of intraarticular steroids in OA. In our unit we avoid intra-articular steroids in patients that are to be placed on the waiting list for TKR. If a patient is not a candidate for TKR and has had a good and lasting response to intra-articular steroid treatment in the past then the injection is repeated. doi:10.1302/0301-620X.89B3.19289

A. V. PAPAVASILIOU, BSc, MD, PhD, Research Registrar in Orthopaedics

Eastbourne District General Hospital,

East Sussex, UK.

1. Gossec L, Dougados M. Intra-articular treatments in osteoarthritis: from the symptomatic to the structure modifying. Ann Rheum Dis 2004;63:478-82.

2. Ayral X. Injections in the treatment of osteoarthritis. Best Pract Res Clin Rheumatol 2001; 15:609-26

3. Kirwan JR, Rankin E. Intra-articular therapy in osteoarthritis. Baillieres Clin Rheumato/ 1997;11:769-94.

4. Creamer P. Intra-articular corticosteroid treatment in osteoarthritis. Curr Opin Rheumatol 1999;11:417-21

5. Friedman DM, Moore ME. The efficacy of intraarticular steroids in osteoarthritis: a double-blind study. J Rheumato/ 1980;7:850-6.

6. Dieppe PA, Sathapatayavongs B, Jones HE, Bacon PA, Ring EF. Intra-articular steroids in osteoarthritis. Rheumatol Rehabil 1980;19:212-17.

7. Jones A, Doherty M. Intra-articular corticosteroids are effective in osteoarthritis but there are no clinical predictors of response. Ann Rheum Dis 1996;55:829-32.

Sir,

I read with interest the paper by Papavasiliou et $\mathrm{al}^{1}$ in the March 2006 issue entitled "Infection in knee replacements after previous injection of intra-articular steroid". Many surgeons anecdotally feel 
that injecting knees with steroid prior to total knee replacement is not advisable. It was interesting to note that the authors did not find any relationship between the number, or timing of, injections and post-operative deep infection. I would like to raise the following queries with the authors.

1. It has been mentioned that the steroid is 'reactivated' in the knee several months after injection. What exactly do they mean by that?

2. From personal experience, I know that many surgeons in North America inject a cocktail of drugs into wounds after total hip and knee replacements, often containing, among others, a long-lasting steroid. The authors quote no increase in post-operative infection rates.

doi:10.1302/0301-620X.89B3.19290

G. N. VASHISTA, MRCS, Specialist Registrar

Barnsley District General Hospital,

Barnsley, South Yorkshire, UK.

1. Papavasiliou AV, Isaac DL, Marimuthu R, Skyrme A, Armitage A. Infection in knee replacements after previous injection of intra-articular steroid. J Bone Joint Surg [Br] 2006;88-B:321-3.

\section{Author's reply:}

Sir,

We thank Mr Vashista for his comments.

1. The length of time between injection of steroids into the knee and subsequent increased risk of post-operative infection lead us to speculate that some of the steroid crystals do not fully dissolve within the knee joint but remain within the surrounding soft tissues or cystic areas of degeneration within the knee. Jones et $\mathrm{al},{ }^{1}$ in a contrast radiography study, reported that one third of injections into the knee are actually extra-articular and within the surrounding soft tissues. At the time of the operation the steroid crystals may be released (reactivated) from the soft tissues finding their way into the operating field.

2. I am not aware of such a practice. I do know that US surgeons inject a cocktail of drugs into knee joint replacements, but for analgesia and haemostasis purposes.

doi:10.1302/0301-620X.89B3.19291

A. V. PAPAVASILIOU, BSc, MD, PhD, Research Registrar in Orthopaedics

Eastbourne District General Hospital,

East Sussex, UK.

1. Jones A, Regan M, Ledingham J, et al. Importance of placement of intra-articular steroid injections. BMJ 1993:307:1329-30.

Sir,

We read with interest the March 2006 paper by Papavasiliou et $\mathrm{al}^{1}$ entitled "Infection in knee replacements after previous injection of intra-articular steroid", and note the authors' hypothesis that "intra-articular steroid injection is associated with a higher incidence of post-operative deep wound infection in total knee replacement".

We would like to make the following points:

1. The authors' diagnostic criteria are not supported by a reference to the evidence base in the literature. The criteria given for both superficial and deep surgical sites of infection appear to be closely related, but not identical, to the National Nosocomial Infection Surveillance (NNIS) guidelines. ${ }^{2,3}$ In the authors' methods, there is no distinction between deep and organ/space-based infections. In the
NNIS criteria intra-articular infection following knee replacement falls into the organ/space-based infection category. The NNIS guidelines make no reference to diagnosis via "pus cells present on microscopy" for deep surgical site infection. Pus cells are present in many inflammatory processes and their presence may not always indicate infection. Of interest, both the authors' and the NNIS guidelines state that both superficial and deep surgical site infections can be diagnosed by an attending clinician alone. This subjective criterion could lead to considerable variation in the diagnosis of infection.

2. Following the pilot study, the authors decided to retrospectively examine the AGC prosthesis. There was no reason stated as to why the AGC prosthesis was chosen. We note that four of the six deep infections (Table I) were found with this prosthesis. Was the AGC prosthesis chosen due to the high, deep infection rate and therefore increased probability of producing a significant difference in deep infection between the two study groups?

3. Table I lists four patients with AGC prostheses that had evidence of deep infection. It was stated in the results that there were only three recorded deep infections, all within Group I. There is no mention of the last patient (case 6, Table I) in the results, nor whether they had received a previous intra-articular steroid injection. doi:10.1302/0301-620X.89B3.19292

N. J. LITTLE, MRSC, MSc, Specialist Registrar

A. CHIPPERFIELD, MRCS, Specialist Registrar

D. M. RICKETTS, FRCS(Orth), Consultant, Orthopaedics and Trauma

Princess Royal Hospital,

Haywards Heath, UK.

1. Papavasiliou AV, Isaac DL, Marimuthu R, Skyrme A, Armitage A. Infection in knee replacements after previous injection of intra-articular steroid. J Bone Joint Surg [Br] 2006;88-B:321-3.

2. Centers for Disease Control (U.S). NNIS manual: NNIS, National Nosocomial Infec tions Surveillance System. Atlanta, Georgia, USA: U.S. Department of Health and Human Services, Public Health Service, Centers for Disease Control and Prevention, 1999

3. Horan TC, Gaynes RP, Martone WJ, Jarvis WR, Emori TG. CDC definitions of nosocomial surgical site infections, 1992: a modification of CDC definitions of surgical would infections. Infect Control Hosp Epidemiol 1992;13:606-8.

\section{Author's reply:}

Sir,

We thank Mr Little et al for raising some points that require further clarification.

During the period of time studied (February 2002 to October 2004), three types of total knee replacement (TKR) were routinely used in our department, namely AGC, IBII and Scorpio. We chose to study the AGC prosthesis for the simple reason that it represented the largest group (231 of 420 patients). By reviewing one type of prosthesis we minimised the variables depending on the type of TKR used, and also reduced the number of surgeons involved. Patient number 6 (Table I) had no evidence of being treated with an intraarticular steroid injection prior to surgery (seen in Table I as N/A not applicable). This patient was excluded from our final study since he did not meet our set strict inclusion criteria. doi:10.1302/0301-620X.89B3.19293

A. V. PAPAVASILIOU, BSc, MD, PhD, Research Registrar in Orthopaedics

Eastbourne District General Hospital,

East Sussex, UK. 